\title{
Seasonal incidence of Haemoprotozoal diseases in crossbred cattle and buffalo in Kaira and Anand districts of Gujarat, India
}

\author{
S P Vahora , J V Patel*, B B Patel, S B Patel, R H Umale \\ Amul Research and Development Association (ARDA), \\ Amul Dairy, Anand 388001, Gujarat, India \\ * Corresponding author email: jvpatel@amuldairy.com \\ Received: 23-09-2011, Accepted: 17-10-2011, Published Online: 19-12-2011 \\ doi: 10.5455/vetworld.2012.223-225
}

\begin{abstract}
Seasonal incidence of haemoprotozoal diseases in crossbred cattle and buffalo was studied by examining 3152 and 1129 blood smears respectively, received from various veterinary sub centres located in Anand and Kaira districts of Gujarat during period from April 2009 to March 2010. The present study has recorded higher incidence of haemoprotozoal diseases in crossbred cattle and buffalo from June to September and June to August, respectively. In crossbred cattle, $1172(37 \%)$ out of 3152 blood smears were positive for haemoprotozoal infection while in buffalo, 191 (17\%) out of 1129 blood smears were positive for haemoprotozoal infection. In both the species, higher incidence of Theileriosis was recorded during monsoon season as compared to other protozoan diseases.
\end{abstract}

Key Words: Seasonal Incidence, Haemoprotozoan, Blood Smears

To cite this article : Vahora SP, Patel JV, Patel BB, Patel SB and Umale RH (2012) Seasonal incidence of Haemoprotozoal diseases in crossbred cattle and buffalo in Kaira and Anand districts of Gujarat, India, Vet. World. 5(3):223-225, doi: 10.5455/vetworld.2012.223-225

\section{Introduction}

Haemoprotozoal diseases cause devastating losses to the livestock industry and so pose major constraints to the dairy industry throughout the world. The hot and humid climate is very favourable for development and survival of ticks and is a constant source of damage. In the absence of appropriate control strategies, the haemoprotozoal diseases have serious economic impact in view of mortality, reduced milk yield and lowered animal draft power which presents a major constraint to bovine production thus hindering agricultural and socio-economic development of vast area in India (Suryanarayan, 1990). Most of the haemoprotozoan parasites are tick borne and is of great economic importance in Asia and has always been a formidable barrier to the survival of cross bred cattle in India. Devendra, (1995) reported the annual loss of US $\$ 800$ million due to tropical theileriosis in India. The babesias are one of the most ubiquitous and widespread blood parasites in the world based on numbers and distribution of species in animals, second only to the trypanosomes (Levine, 1988 and Telford et al., 1994). Trypanosomosis caused by Tryponosoma evansi is also an important haemoprotozoan disease of domesticated animals. Among the several species of trypanosomes, Trypanosoma evansi is the most commonly occurring species in India causing the disease (Pathak et al., 2005).

The present investigation has recorded the month wise infection of Theileriosis, Babesiosis, Anaplasmosis and Trypnasomiasis in crossbred cattle and buffaloes.

\section{Materials and Methods}

During the period from April 2009 to March 2010, a total of 3152 blood smears of crossbred cattle and 1129 blood smears of buffaloes in Anand and Kaira districts of Gujarat and manifesting clinical signs viz., high temperature, anaemia, enlargement of lymph nodes, haemo-globinuria, circling movement, nasal discharge, coughing, grinding of teeth, sudden drop in milk yield and abortion were screened for various haemoprotozoal diseases. The blood smears were stained with Leishman's stain (Qualigens) and examined under oil immersion microscope.

\section{Results and Discussion}

The study was conducted for one year to observe 
Table-1: Month wise incidence of Haemoprotozoal diseases detected in crossbred cattle and buffalo during April 2009-March 2010.

\begin{tabular}{|c|c|c|c|c|c|c|c|c|c|}
\hline Species & Month & Theileriosis & Babesiosis & Anaplasmosis & Trypanosomiasis & $\begin{array}{c}\text { Mixed } \\
\text { Infection }\end{array}$ & $\begin{array}{c}\text { Total } \\
\text { Positive cases }\end{array}$ & $\begin{array}{c}\text { Total } \\
\text { blood smears }\end{array}$ & $\begin{array}{l}\% \text { of positive } \\
\text { cases }\end{array}$ \\
\hline Buffalo & $\begin{array}{l}\text { April } \\
\text { May } \\
\text { June } \\
\text { July } \\
\text { Aug } \\
\text { Sep. } \\
\text { Oct } \\
\text { Nov } \\
\text { Dec } \\
\text { Jan } \\
\text { Feb } \\
\text { March } \\
\text { Total } \\
\%\end{array}$ & $\begin{array}{c}7 \\
9 \\
37 \\
27 \\
16 \\
12 \\
5 \\
8 \\
6 \\
7 \\
16 \\
11 \\
\mathbf{1 6 1} \\
\mathbf{8 4 . 2 9}\end{array}$ & $\begin{array}{l}1 \\
2 \\
0 \\
0 \\
2 \\
0 \\
0 \\
1 \\
0 \\
0 \\
1 \\
0 \\
\mathbf{7} \\
\mathbf{3 . 6 6}\end{array}$ & $\begin{array}{l}0 \\
0 \\
0 \\
0 \\
0 \\
0 \\
0 \\
0 \\
0 \\
0 \\
0 \\
0 \\
\mathbf{0} \\
\mathbf{0}\end{array}$ & $\begin{array}{c}2 \\
4 \\
4 \\
5 \\
2 \\
1 \\
0 \\
1 \\
2 \\
1 \\
0 \\
1 \\
\mathbf{2 3} \\
\mathbf{1 2 . 0 4}\end{array}$ & $\begin{array}{l}0 \\
0 \\
0 \\
0 \\
0 \\
0 \\
0 \\
0 \\
0 \\
0 \\
0 \\
0 \\
0 \\
0\end{array}$ & $\begin{array}{c}10 \\
15 \\
41 \\
32 \\
20 \\
13 \\
5 \\
10 \\
8 \\
8 \\
17 \\
12 \\
191\end{array}$ & $\begin{array}{c}84 \\
156 \\
139 \\
151 \\
106 \\
58 \\
76 \\
51 \\
43 \\
75 \\
112 \\
78 \\
\mathbf{1 1 2 9}\end{array}$ & $\begin{array}{c}21 \\
28 \\
16 \\
9 \\
5 \\
28 \\
7 \\
27 \\
19 \\
11 \\
20 \\
21 \\
17\end{array}$ \\
\hline
\end{tabular}

the seasonal prevalence, there was a considerable seasonal variation found with the occurance of haemoprotozoan diseases in animals. The results of the study are presented in (Table-1). Higher incidences of haemoprotozoal diseases in crossbred cattle and buffalo reported during June to September and June to August, respectively which is in accordance with the observation made by Radostits et al., (1994), Roy et al., (2004) and Ananda et al., (2009) they found the highest prevalence of haemoprotozoal infection in monsoon months.

The examination of 3152 blood smears from crossbred cattle and 1129 blood smears buffalo, 1172 (37\%) positive cases from crossbred cattle and 191 (17\%) positive cases from buffalo were reported during this period. This indicated that the incidences were higher in crossbred cattle than the buffalo. This result of crossbred cattle (37\%) was in line with the result observed by Ananda et al., (2009) the prevalence in crossbred cattle was $43.1 \%$.

Among Haemoprotozoan diseases, the incidence of Theileriosis was higher during monsoon in crossbred cattle and buffalo reported $82.94 \%$ and $84.29 \%$ respectively as compared to other haemoprotozoan diseases. This result supports the earlier study of Theileriosis infection (Jithendran, 1998) who recorded cases of theileriosis are generally observed during summer or rainy season when the ticks have higher activity although sporadic outbreaks have been recorded year round. Results on prevalence of
Theileriosis in crossbred cattle $(82.94 \%)$ was in accordance with Ananda et al., (2009) who recorded $72 \%$ prevalence of Theileriosis in crossbred cattle.

The overall incidences of Babesiosis, Anaplasmosis, Trypanosomiasis and Mixed Infections in crossbred cattle were $10.41 \%, 2.82 \%, 1.11 \%$ and $2.73 \%$ respectively while in buffalo the overall incidences of Babesiosis and Trypanosomiasis were $3.66 \%$ and $12.04 \%$ respectively. Our results on Babesiosis infection was in accordance with the observation made by Seyyed et al., (2011) the incidence of Babesiosis infection was $9.76 \%$. In buffalo, there was not reported single case of Anaplasmosis and Mixed infections.

\section{Acknowledgements}

This work received financial support from the Amul Research and Development Association (ARDA). The authors also wish to thank the all veterinarians who kindly provided clinical data concerning haematozoan-infected animals from field condition.

\section{Conflict of interest}

Authors declare that they have no conflict of interest.

\section{References}

1. Ananda, K. J., D'Souza, P. E. and Puttalakshmamma, G. C. (2009). Prevalence of Haemoprotozoan diseases in crossbred cattle in Banglore north. Vet. World. 2(1): 15-16. 
2. Devendra, C. (1995): In Global Agenda for Livestock research, EDS, ILRI, Nairobi., pp: 41-48.

3. Jithendran, K.P. and Sharma, A.K. (1998). A case of theileriosis in a cow: A case report. Indian Vet. Med. J., 22: $251-252$.

4. Levine, N. D. (1988). The protozoan phylum Apicomplexa, vol. 2. CRC Press, Boca Raton, Fla.

5. Pathak, K. M. L. and Singh, N. (2005). Animal trypanosomosis. Intas Polivet, 6(11):194-199.

6. Radostits, O.M., Blood, D. C. and Gay, C.C. (1994): Veterinary Medicine, A Text book of the disease, sheep, Goats, Pgs and Horse, $8^{\text {th }}$ edn. ELBS, Baillier, London.

7. Roy, S., Tiwari, A., Galdhar, C.N., Upadhyay, S.R.,
Ratre, H.K., S.K. and Maiti, S.K. (2004): Indian J Vet.Med.24:5-7.

8. Seyyed, P. Z., behzad, E. and Mohammad, R. Y. (2011). Study of the Prevalence of Babesiosis in Domesticated Animals with Suspected Signs in Mazandaran Province, North of Iran, During 2008. J. Ani.Vet.Adv., 10 (6): 712-714.

9. Suryanarayana, C. (1990): A review of hematological and biochemical picture in haemoprotozoan disease of cattle. Livestock Advisor 15: 15-20.

10. Telford, S. R., III, A. Gorenflot, P. Brasseur, and A Spielman. (1994). Babesial infections in humans and wildlife, p. 1-47. In J.P. Kreier (ed.), Parasitic protozoa, 2nd ed., vol. 5. Academic Press, San Diego. 